University of Wollongong

Research Online

Faculty of Social Sciences - Papers (Archive) Faculty of Arts, Social Sciences \& Humanities

2012

How feasible are lifestyle modification programs for disease prevention in general practice?

Heike Schutze

University of Wollongong, hschutze@uow.edu.au

Elizabeth F. Rix

University of Sydney

Rachel A. Laws

University of Sydney, rlaws@uow.edu.au

Megan Passey

University of Sydney

Mahnaz Fanaian

University of New South Wales, mahnaz@uow.edu.au

See next page for additional authors

Follow this and additional works at: https://ro.uow.edu.au/sspapers

Part of the Education Commons, and the Social and Behavioral Sciences Commons

Research Online is the open access institutional repository for the University of Wollongong. For further information contact the UOW Library: research-pubs@uow.edu.au 


\title{
How feasible are lifestyle modification programs for disease prevention in general practice?
}

\begin{abstract}
Vascular disease is a leading cause of death and disability. While it is preventable, little is known about the feasibility or acceptability of implementing interventions to prevent vascular disease in Australian primary health care. We conducted a cluster randomised controlled trial assessing prevention of vascular disease in patients aged $40-65$ by providing a lifestyle modification program in general practice. Interviews with 13 general practices in the intervention arm of this trial examined their views on implementing the lifestyle modification program in general practice settings. Qualitative study, involving thematic analysis of semi-structured interviews with 11 general practitioners, four practice nurses and five allied health providers between October 2009 and April 2010. Providing brief lifestyle intervention fitted well with routine health-check consultations; however, acceptance and referral to the program was dependent on the level of facilitation provided by program coordinators. Respondents reported that patients engaged with the advice and strategies provided in the program, which helped them make lifestyle changes. Practice nurse involvement was important to sustaining implementation in general practice, while the lack of referral services for people at risk of developing vascular disease threatens maintenance of lifestyle changes as few respondents thought patients would continue lifestyle changes without long-term follow up. Lifestyle modification programs to prevent vascular disease are feasible in general practice but must be provided in a flexible format, such as being offered out of hours to facilitate uptake, with ongoing support and follow up to assist maintenance. The newly formed Medicare Locals may have an important role in facilitating lifestyle modification programs for this target group.
\end{abstract}

\section{Keywords}

prevention, programs, feasible, lifestyle, disease, modification, general, practice?

\section{Disciplines}

Education | Social and Behavioral Sciences

\section{Publication Details}

Schutze, H., Rix, E. F., Laws, R. A., Passey, M., Fanaian, M. \& Harris, M. F. (2012). How feasible are lifestyle modification programs for disease prevention in general practice?. Australian Journal of Primary Health, 18 (2), 129-137.

\section{Authors}

Heike Schutze, Elizabeth F. Rix, Rachel A. Laws, Megan Passey, Mahnaz Fanaian, and Mark F. Harris 


\title{
How feasible are lifestyle modification programs for disease prevention in general practice?
}

\author{
Heike Schütze ${ }^{\mathrm{A}}$, Elizabeth F. Rix ${ }^{\mathrm{B}}$, Rachel A. Laws ${ }^{\mathrm{C}}$, Megan Passey $^{\mathrm{B}}$, Mahnaz Fanaian ${ }^{\mathrm{A}}$ \\ and Mark F. Harris A, D \\ A Centre for Primary Health Care and Equity, UNSW, L3 AGSM, Faculty of Medicine, \\ University of New South Wales, Sydney, NSW 2052, Australia. \\ ${ }^{B}$ Northern Rivers Department of Rural Health, School of Public Health, University of Sydney, \\ Lismore, NSW 2480, Australia.

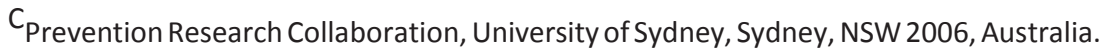 \\ D Corresponding author. Email: m.f.harris@unsw.edu.au
}

\begin{abstract}
Background: Vascular disease is a leading cause of death and disability. While it is preventable, little is known about the feasibility or acceptability of implementing interventions to prevent vascular disease in Australian primary health care. We conducted a cluster randomised controlled trial assessing prevention of vascular disease in patients aged $40-65$ by providing a lifestyle modification program in general practice. Interviews with 13 general practices in the intervention arm of this trial examined their views on implementing the lifestyle modification program in general practice settings. Methods: Qualitative study, involving thematic analysis of semi-structured interviews with 11 general practitioners, four practice nurses and five allied health providers between October 2009 and April 2010. Results: Providing brief lifestyle intervention fitted well with routine health- check consultations; however, acceptance and referral to the program was dependent on the level of facilitation provided by program coordinators. Respondents reported that patients engaged with the advice and strategies provided in the program, which helped them make lifestyle changes. Practice nurse involvement was important to sustaining implementation in general practice, while the lack of referral services for people at risk of developing vascular disease threatens maintenance of lifestyle changes as few respondents thought patients would continue lifestyle changes without long-term follow up. Conclusion: Lifestyle modification programs to prevent vascular disease are feasible in general practice but must be provided in a flexible format, such as being offered out of hours to facilitate uptake, with ongoing support and follow up to assist maintenance. The newly formed Medicare Locals may have an important role in facilitating lifestyle modification programs for this target group.
\end{abstract}

Additional keywords: diabetes prevention, primary health care, sustainability of lifestyle changes, vascular disease prevention. 


\section{Introduction}

Chronic conditions are a major contributor to the burden of disease both internationally (WHO 2000) and in Australia, where they account for nearly $80 \%$ of the overall burden of disease (AlHW 2008). A leading cause of death and disability in Australia is vascular disease (cardiovascular disease, diabetes or renal disease), affecting $18 \%$ of the population (AIHW 2008). With a large proportion of consultations in Australian general practice being for vascular disease (Britt et al. 2009), prevention is a high priority at all levels of government (DoHA 2009).

Modifiable lifestyle risk factors for vascular disease include smoking, poor nutrition, excess alcohol, inadequate physical activity and excess weight (SNAPW) (AIHW 2008). Other risk factors for vascular disease, such as hypertension and hyperlipidaemia, can also be modified with changes in lifestyle. Brief interventions by general practitioners in the form of offering advice and providing information can be effective in promoting healthy lifestyle changes (Goodwin et al. 2001; Hogg et al. 2008; Sim et al. 2009). Brief interventions can form part of routine care in general practice, and unlike generic health information, can be tailored to the individual's needs. However, these brief interventions are often not enough to alter behaviour (Sim et al. 2009) or to bring about sufficient physiological change to reduce the risk of vascular disease. Patients often require more intensive interventions through referrals to external support services, such as individual or group counselling programs (Eley and Eley 2009).

In 2006, the Council of Australian Governments 'Plan for Better Health for All Australians' called for the development and implementation of lifestyle modification programs (LMP) to prevent diabetes (COAG 2006). This specifically identified the importance of the assessment and management of the SNAPW risk factors in general practice.

Following this, the Australian government introduced a program that included diabetes risk assessment visits for patients aged 40-49 years in addition to health checks for patients aged 45-49 years, with referral of high risk patients to group LMPs provided through Divisions of General Practice (AGPN 2009). These LMPsconsist of a series of group education and motivation sessions supporting lifestyle change. Information provided at the LMPs includes strategies for adopting and maintaining healthy lifestyle changes, such as improved nutrition and physical activity, smoking cessation and reduced alcohol consumption. They also emphasise the need for regular diabetes screening and how to access community resourcesforongoing support in maintaining lifestyle change (AGPN 2009; DoHA 2010b).

The uptake of these health assessments and referral of at- risk patients has been lower than expected (Fig. 1). Factors contributing to this include lack of time, limited availability of referral services, cost of private services, inadequate financial compensation and perceived low motivation of patients (Harris et al. 2005; Amoroso et al. 2009; Passey et al. 2010).

While there has been considerable work on interventions to prevent diabetes in high risk patients (Tuomilehto et al. 2001; Diabetes Prevention Program Research Group 2002), there has been little work on how interventions to prevent vascular disease fit with general practice in Australia (Wan et al. 2008), nor on how effective they are when implemented as part of routine care systems (Harris et al. 2003). To our knowledge, the Health Improvement Prevention Study (HIPS) (Fanaian et al. 2010) is the first study to explore how a LMP for patients at risk of vascular disease (not just diabetes) can be implemented into general practice in Australia. This study explores the views of general practitioners (GPs), practice nurses (PNs) and allied health (AH) providers involved in a cluster randomised controlled trial of prevention of vascular disease. The HIPS intervention included a health check in general practice followed by referral of at-risk patients to a group LMP. The aim of this sub-study was to explore providers' views on implementing the HIPS intervention into general practice routines, their perceptions of the impact on patients, and opportunities for improvement.

\section{Methods}

\section{Context}

The study was conducted in five Divisions of General Practice (Divisions) in the state of NSW, Australia: two in rural NSW and three in urban Sydney. The socio-demographic make-up of the population served by the Divisions is provided in Table 1. Divisions are primary health care organisations that provide services and support to general practice at the local level including education to GPs and practice staff aimed at quality improvement (DoHA 2010a). 


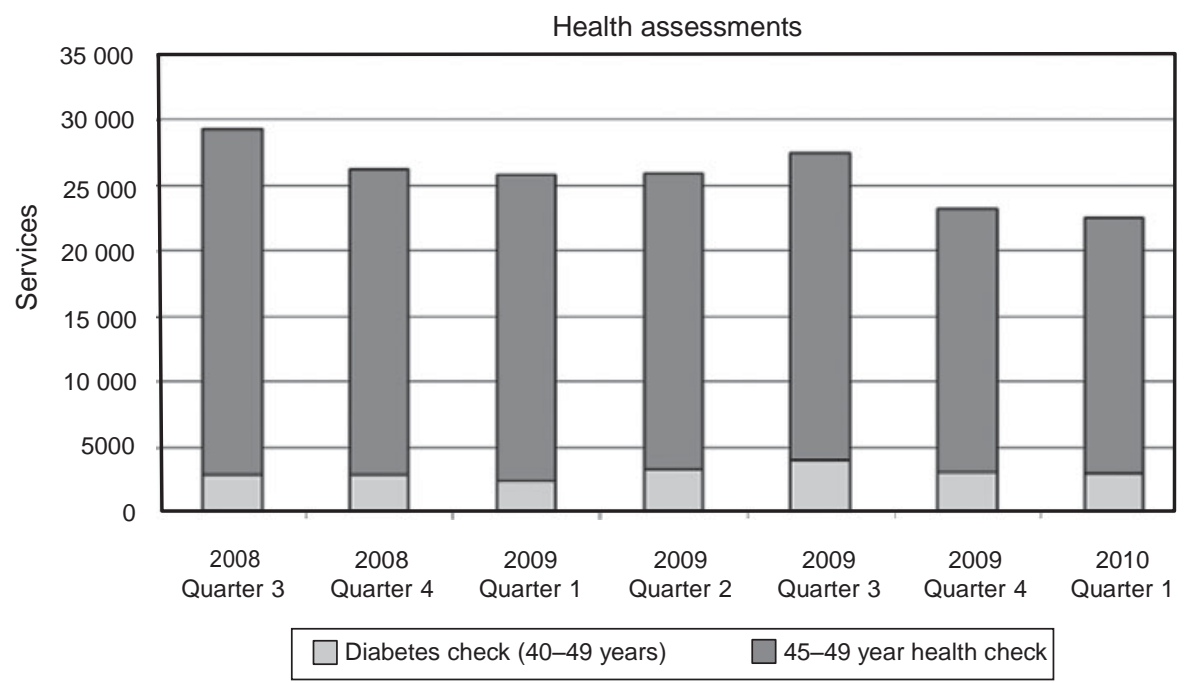

Fig. 1. Medicare health check item use. Quarter 32008 to Quarter 1 2010: items 717 45-49-year-old health check; item 713 type 2 diabetes risk evaluation. Source: Medicare Australia 2011.

Table 1. Division demographics

$\mathrm{ND}$, no data

\begin{tabular}{|c|c|c|c|c|c|c|c|}
\hline Division & Total population & $\begin{array}{c}65+\text { years } \\
\text { (\% total pop.) }\end{array}$ & $\begin{array}{c}<25 \text { years } \\
(\% \text { total pop. })\end{array}$ & $\begin{array}{l}\text { Australian born } \\
\text { (\% total pop.) }\end{array}$ & $\begin{array}{l}\text { Unemployed } \\
\text { (\% total pop.) }\end{array}$ & $\begin{array}{l}\text { No. of general } \\
\text { practices }\end{array}$ & $\begin{array}{l}\text { No. of } \\
\text { GPs }\end{array}$ \\
\hline \#1 (Urban) & $500000-599000$ & $50000-59000(10 \%)$ & $40000-49000(10 \%)$ & $70000-79000(15 \%)$ & $9000-9900(2 \%)$ & $300-399$ & $600-699$ \\
\hline \#3 (Rural) & $150000-199000$ & $20000-29000(15 \%)$ & $50000-59000(30 \%)$ & ND & ND & $50-99$ & $200-299$ \\
\hline \#4 (Rural) & $100000-149000$ & $10000-19000(15 \%)$ & $30000-39000(35 \%)$ & $70000-79000(75 \%)$ & $2000-2900(2 \%)$ & $0-49$ & 0-99 \\
\hline \#5 (Urban) & $150000-199000$ & $20000-29000(15 \%)$ & $40000-49000(25 \%)$ & $100000-149000(60 \%)$ & $8000-8900(5 \%)$ & $150-199$ & $400-500$ \\
\hline
\end{tabular}

Source: Primary Health Care Research and Information Service. Division and SBO profiles (PHCRIS 2011). 
Participant recruitment and study context

The main project, HIPS, was a cluster randomised controlled trial of a general practice LMP intervention to prevent vascular disease. It targeted patients aged 40-65 and was conducted in 30 practices across NSW (rural $n=14$, urban $n=$ 16) (Fanaian et al. 2010). In total, 958 patients were recruited for HIPS (448 patients from intervention practices) and informed written consent was obtained from all participants. The HIPS intervention aimed to assist high risk patients make positive lifestyle changes by providing a brief intervention tailored to patients' stage of change. This was done as part of a health check in general practice, with referral of high risk patients to a LMP coordinated by trained facilitators at local Divisions. The LMP comprised two AH visits (at the AH provider's practice) and four group sessions of $1.5 \mathrm{~h}$ each over a three month period with follow-up review sessions at six and nine months. The group sessions were held either at the Division offices, or at local venues, such as halls, which were hired for the purpose. The role of the Division facilitator was to coordinate and run the group sessions. Each group session

included an educational component as well as a physical activity component consisting of 20-30 min of walking or resistance exercise. The group sessions were based on the use of self- management strategies, such as selfmonitoring, goal setting, problem solving and developing practical skills to promote weight loss through positive physical activity and dietary changes. Some Divisions facilitated participation in the LMP by providing taxi vouchers for participants to enable transport to and from the LMP, and/or offering the group sessions out of business hours. Further details of the HIPS protocol are reported elsewhere (Fanaian et al. 2010).

For this qualitative sub-study, GPs and PNs from all 18 intervention practices, as well as the six AH providers that helped deliver the intervention were invited to participate in the interviews. Providers were mailed a letter informing them that they would be contacted by phone and invited to be interviewed regarding the intervention. Thirteen intervention practices and five AH providers agreed to participate and informed consent was obtained from all participants.

\section{Data collection}

Semi-structured interviews were conducted with GPs and PNs from 13 intervention practices (rural $n=7$, urban $n=6$ ) and with five $\mathrm{AH}$ providers (rural $n=4$, urban $n=1$ ). A total of 20 interviews were conducted over the telephone $(n=15)$ or face-to- face $(n=5)$, between October 2009 and April 2010. All interviews were audio taped with the exception of one rural PN who was not comfortable being audio taped. Responses for this respondent were written at the time of the interview. Interviews were performed by four experienced members of the research team following a series of standard questions that allowed for flexibility around responses. Respondents were asked six broad questions about their overall experience of participating in the HIPS intervention, including referring patients to the LMP and providing follow up for patients, as well as their perceptions of how the patients went in making the suggested lifestyle changes and what plans their practice had in the future for providing preventive care for patients at risk of cardiovascular disease. Demographic information about respondents was collected in the main HIPS study.

\section{Data analysis}

Transcribed interviews were analysed using the qualitative software tool QSR Nvivo 8 (QSR International 2008), a computer program to assist with coding and organising data. The chief investigator and an experienced researcher collaboratively analysed a selection of transcripts to elicit a base coding frame and broad common themes. This first version of the coding scheme was then discussed with a second coder to establish a common understanding of the codes. One researcher independently coded all the transcripts adding to the base coding framework. Hence, the code frame was developed based on a mixed deductive and inductive approach (Boyatzis 1998). The codes were derived theoretically, taking into account the research questions, the normalisation theory (May et al. 2007) and knowledge regarding LMPs and general practice. Themes were also identified from the transcripts, which provided the foundation for modifying the codes developed by induction or for generating new codes. Using the method of Boyatzis (1998) to ensure high inter-rater reliability, the transcripts were again coded using the same code frame by the second coder. Any divergence in coding was discussed by both coders at length, with themes added or modified until there was concordance on the coding.

\section{Ethical approval}

HIPS (NHMRC Project 510173) and this subsequent investigation were approved by the University of New South Wales Human Research Ethics Committee. 


\section{Findings}

Respondents were evenly spread in terms of age, gender, years of experience, hours of work per week, rurality, number of GPsin the practice and mode of billing (see Table2). The sample has similar characteristics to providers in NSW (Britt et al. 2009).

Emergent themes from the qualitative interviews fell into five broad areas.

\section{Fit with general practice routines}

The ease with which assessment and brief advice for lifestyle modification could be incorporated into normal routine practice was an important issue for GPs and PNs. General practitioners reported that offering brief advice regarding lifestyle modifications was quite easy to incorporate as part of a health check consultation. Many GPs reported that this was already part of their normal practice and some felt that they were already proactive with preventative lifestyle measures for their at-risk patients. They reported previously offering advice, providing printed material, and arranging referral for at least some of their patients.

The training and practice support provided to GPs and AH providers as part of the project allowed a more systematic and planned approach to preventive care.

We already were doing quite a lot of ... those things in a lot of patients... So we were oriented towards that already anyway. (GP \#2)

Table 2. Respondent demographics

N/A, not applicable; ND, no data

\begin{tabular}{|c|c|c|c|c|c|c|c|}
\hline ID & Rurality & Gender & $\begin{array}{l}\text { Age group } \\
\text { (years) }\end{array}$ & $\begin{array}{c}\text { Experience } \\
\text { (years) }\end{array}$ & $\begin{array}{l}\text { Hours work } \\
\text { per week }\end{array}$ & $\begin{array}{l}\text { No. of GPs } \\
\text { in practice }\end{array}$ & $\begin{array}{c}\text { Billing } \\
\text { mode }\end{array}$ \\
\hline GP \#1 & Rural & Female & $35-44$ & 20 & 41 & 3 & Private \\
\hline GP \#2 & Rural & Male & $35-44$ & 25 & 40 & 4 & Private \\
\hline GP \#3 & Rural & Male & $35-44$ & 23 & 45 & 8 & Private \\
\hline GP \#4 & Rural & Male & $45-54$ & 20 & 35 & 2 & Private \\
\hline GP \#5 & Rural & Female & $45-54$ & 20 & 40 & 4 & Private \\
\hline GP \#6 & Urban & Female & $35-44$ & 15 & 52 & 2 & Bulk bill \\
\hline GP \#7 & Urban & Male & $45-54$ & 17 & 40 & 2 & Bulk bill \\
\hline GP \#8 & Urban & Male & $55-64$ & 35 & 55 & 2 & Private \\
\hline GP \#9 & Urban & Female & $45-54$ & 26 & 35 & 6 & Private \\
\hline GP \#10 & Urban & Female & $45-54$ & 39 & 25 & 2 & Bulk bill \\
\hline PN \#1 & Rural & Female & $45-54$ & 2.5 & 40 & 1 & Bulk bill \\
\hline $\mathrm{PN} \# 2$ & Rural & Female & $55-64$ & 4 & 16 & 2 & Private \\
\hline PN \#3 & Rural & Male & $35-44$ & 20 & 32 & 5 & Private \\
\hline $\mathrm{PN} \# 4$ & Rural & Female & $45-54$ & 15 & 16 & 4 & Private \\
\hline PN \#5 & Urban & Male & $25-34$ & ND & 40 & 6 & Bulk bill \\
\hline AHP \#1 & Rural & Female & $25-34$ & 7 & ND & N/A & N/A \\
\hline AHP \#2 & Rural & Male & $35-44$ & 8 & 38 & N/A & N/A \\
\hline AHP \#3 & Rural & Male & $35-44$ & 10 & 38 & N/A & N/A \\
\hline AHP \#4 & Rural & Female & $45-54$ & 3 & 38 & N/A & N/A \\
\hline AHP \#5 & Urban & Female & $25-34$ & 3 & 38 & N/A & N/A \\
\hline
\end{tabular}

One GP suggested that it would have been better to have more materials on the computer to print out and an electronic form to aid in the assessment of patients. Some suggested the use of a standardised form would aid monitoring and follow up.

It'd be easier on review to have a standardised form, the same as in the initial assessment ... to be able to repeat that process ... at the follow-up visit would actually have been really useful and they could have got the original one out, compared it ... with the next one and made direct comparisons with the patient: 'Look you know you were drinking 20 drinks a day and now you're down to four.' (GP \#1) 
Some respondents appreciated the recall of patients to the practice for a specific health check visit, especially because this encouraged the more motivated patients to present. Others felt health checks should be performed on all their patients to allow earlier detection and prevention of chronic disease.

It links in very well with the fact that we should be doing our health checks on everybody that walks in here... So that you can pick up things before they get to a stage... (PN\#1)

Communication with the AH providers and group program

The communication with the AH providers and group program was an issue discussed by many respondents. Most GPs found referral to be easy; however, this was dependent on the quality of organisation provided by individual Division coordinators. In one rural practice, the organisation by the Division was lacking, leading to considerable frustration. Several respondents felt that the relationship of the practice with the Division coordinator was critical to the success of the program.

... it really does help ifsomeone comes into the practice and you can relate to that person who's involved with the program ... so that it's not just left to say one motivated doctor to make sure things happen or one motivated nurse. It's actually easier. So a lot of the success of the program here I think is, is a personality thing that [name of facilitator] has - is very approachable ... the value of the actual person who's running the program to be able to give support and have availability to the patients but to the practice staff as well. (GP $\# 1)$

The major criticism was the lack of feedback from the AH provider to the GP. This disappointed most GPs as they wanted to know whether the patient had been to see the AH providers and what goals had been set so that they could provide ongoing encouragement.

I really haven't had a feedback from the actual program itself yeah. That's the thing with the HIPS study; we haven't had a feedback from the exercise physiologist or the dietitian. There's no information coming to us. (GP \#2)

Perceptions of their patients' experience

In discussing their views of their patients' experience of the group program and AH support, respondents were generally enthusiastic, although some access issues were also identified. Respondents reported that their patients had relayed very positive experiences of the LMP, and GPs perception was that their patients had gained health literacy and awareness. This was helped by the demonstrations and practical exercises patients received in the LMP on changing their diet and physical activity. GPs felt that this was more structured and detailed than they were able to provide in brief consultations and also reinforced the health messages that they gave in the consultation.

You know usually when I see the patient, I, I tell them what to do. But I don't, I don't cook for them. I don't order meal for them ... if I refer patient to a dietitian or exercise physiologist or something like that ... they don't give the patient the practice... I advise the patient you, you, you give the practice, the practical part of what I'm telling patients... make my advice become real. (GP \#8)

Respondents reported that they felt that the realistic goal setting that was encouraged in the LMP was important to helping patients make lifestyle changes as was the group support patients received from peers in the LMP.

I think having a social support, umm, in the group meetings was very important ... I could see the difference in patients between session 1 and 2 just sort of saying, 'Oh well I can do it if I, if I set something small and realistic.' (AH provider \#1)

Although it was mostly motivated patients who attended the group program, respondents also reported involvement of patients still contemplating change. Respondents reported that their patients engaged with the advice given and this helped to motivate and support them to make lifestyle changes. The LMP provided encouragement for patients to take a more active role in their own health care.

I found that people who are ready to change took the info and did the interventions [and] were motivated. Others did not, but most made some small change, which is positive, anything is better than nothing. Some have readily taken exercise on board. (PN \#2)

The biggest barrier to accessing the program both in the urban and rural areas was transport. For patients who worked or had family commitments, the availability of the program out-of-hours was also an issue.

... if these people are working they can't unless it's delivered in the hours that are suitable ... you're talking about you know targeting people in their 30s, 40s, 50s and they're still working. (GP \#7) 
Several respondents reported that cost would also have been a barrier had the group program and $\mathrm{AH}$ visits not been provided free of charge to the patient.

\section{Sustainability of implementing LMPs in primary health care}

Respondents discussed several issues related to the practicalities of providing an intervention such as the HIPS LMP on an ongoing basis. The major barriers reported to greater implementation in general practice were time and competing priorities with other health issues, especially in older patients with existing chronic illness. Providers reported that they were able to incorporate risk factor assessment more routinely and comprehensively than previously because the focus of the consultation was the health check and therefore they had more time for it.

... this was, you know, a deliberate one, a consultation, which was specifically catered to their, umm, problems from that end. (GP \#6)

Practice nurse involvement was seen as an important factor in long-term sustainability and effectiveness of the LMP as they were able to carry out many of the initial and follow-up assessment measurements and offer brief advice tailored to the patient's readiness for change. Additionally, referral appointments and follow-up visits for patients could be arranged by other practice staff.

... a lot of patients, before they see the doctor they see the nurse first who'll take their smoking history, their alcohol history, measure their weight, will offer brief intervention. (GP \#1)

Most appreciated the LMP and were keen to see it provided on an ongoing basis. Many respondents recognised that there were limited services routinely available and there was a need to develop local programs. In particular, respondents felt that there was a need for preventive services for people at risk of developing chronic disease and these were currently lacking in the health system.

And there are a lot of things available for people with conditions... Not so much for ones who are trying to be proactive. (GP \#7)

\section{Sustaining lifestyle changes}

The challenge for patients in maintaining their lifestyle changes was raised by many respondents. Continuity of care was a major factor influencing how successfully the LMP could be sustained and how well patients maintained their lifestyle changes. Few respondents felt that their patients would maintain their lifestyle changes without long-term follow up and that services were required to support this. One GP suggested that there needed to be more phone support of patients once they had completed the LMP. In addition to improving the referral pathway, respondents saw a need for continued efforts to increase patient awareness of LMPs (including establishing long-term LMPs) and to ensure follow up.

... there needs to be, umm, regular contact, regular you know updates and checking in ... you can tell someone to do [things] in about a minute ... but actually getting them to do it is a whole different story... because you've got to change habits and, and you can only change habits by repetition ... it's not like a weight loss antibiotic or a health antibiotic... The best way to really gauge anything is look at them after a significant amount of time once it's finished ... because people will do things while there's someone there ... but once the personal trainer's not around anymore how many people actually keep doing it? (AH provider \#2)

Discussion

The HIPS intervention aimed to provide a locally accessible lifestyle modification program (LMP) for patients at risk of vascular disease, which was facilitated by Divisions and integrated with general practice health checks. This paper describes the views of GPs, PNs and AH providers regarding incorporating this approach in general practice and the feasibility of making programs like this one a permanent addition to primary care strategies. Respondents reported that the HIPS LMP was easily incorporated into routine general practice, was effective in reinforcing GP advice and supported patient behaviour change regarding lifestyle choices. The practical experience offered in the LMP was seen as particularly important. Key facilitators of the LMP identified were: the role of the Division coordinator in arranging referrals to the program and their relationship with the practice; PN involvement in the health assessments; and the continuity of the provider-patient relationship. Respondents felt that the lack of referral services for people at risk of vascular disease in the health system threatened sustainability as few felt that their patients would continue their lifestyle changes without long-term follow up.

\section{Fit with general practice}

Complex interventions can be effectively implemented in health care when they are embedded as part of the normal everyday practice, and when they have been integrated into normal everyday routines they are said to have become normalised (May et al. 2007). Providers found the HIPS health check assessment and offering brief advice tailored to the patient's stage of change was easy to adopt as normal routine as part of a health check consultation. Many 
practitioners were already proactive with their at-risk patients, providing advice, printed materials and $\mathrm{AH}$ referrals; hence the health check assessment was already similar to their usual practice.

Time and other demands have been identified as major barriers to more effective assessment and intervention for preventive care in general practice (Young and Ward 2001; Yarnall et al. 2003; Brotons et al. 2005; Harris et al. 2005; Amoroso et al. 2009; Passey et al. 2010). Providers reported that the HIPS pro forma assessment tool used for measuring patient risk and readiness-to- change made assessment quite easy. They reported that they were able to incorporate assessment more routinely and comprehensively than previously because the specific health check consultation gave them thetime needed andallowed a more systematic approach to preventive care.

The level of facilitation by Division coordinators was considered crucial to acceptance of the program in the practice. This was because of the complexity of the referral pathway to a group LMP (including flexible and responsive scheduling of group LMP sessions, minimising waiting times and providing feedback). Most GPs found the referral process coordinated through the Division to be satisfactory. However, they felt that the quality of reporting back to GPs was deficient and that this was critical for GPs and PNs to be able to provide follow-up support, reinforcement and monitoring for patients who have completed LMPs. Communication back from referral programs is a major challenge for programs aiming to better integrate with general practice (Jackson 2010). While there is real potential for 'normalisation' of the HIPS intervention, further refinements are required to fully integrate and sustain the referral process into practice.

Some respondents felt that the recall of patients specifically for a health check visit encouraged the more motivated patients to present; while others felt health checks should be performed on all of their patients to screen for and prevent chronic disease. Approximately 90\% of the Australian population visit their GP every year (Frank et al. 2004; DoHA 2005), placing GPs in an optimal position to screen for patients at risk of chronic vascular disease. Although lifestyle interventions in primary care are highly cost effective (Eriksson et al. 2010), the uptake of preventive activities opportunistically by GPs in Australia is low (Frank et al. 2004). Implementing a specific health check item number for screening all at-risk patients up to the age of 65 has the potential to overcome this. This could be achieved by extending the current adult health check, which is currently limited to a one- off health check for 45-49-year-olds (DoHA 2006).

\section{Factors affecting lifestyle behaviour change}

Programs for any target group must be affordable and accessible. The target population for vascular disease prevention programs is the 40-65-year-old age group. Many of these people are still in the workforce and/or have family commitments. The main barriers identified in the HIPS LMP were transportation and the availability of the group program out-of-hours. Uptake of the group program was greatly facilitated in the Divisions that provided it out-ofhours. Programs targeting this age group must therefore be delivered in flexible format to better engage participants, including being offered out-of-hours in the evenings and on weekends.

Health literacy is among the many factors influencing patient behaviour. Other factors include: the relevance of information to person's own condition; the person's ability and motivation to make changes; the accessibility, range, cost and suitability of programs readily available to them (Nutbeam and Harris 2004; Sim et al. 2009); as well as realistic goal setting and group social support (Spahn et al. 2010). Lower levels of health literacy have been linked to poorer health outcomes and a reduction in peoples' motivation to participate in health promoting behaviours (Taggart et al. 2010). Providers in the HIPS study felt that their patients had gained health literacy and awareness by participating in the LMP and that they engaged with the advice given. The benefits of realistic goal setting and the group social support in facilitating lifestyle change reported by providers is in line with existing research on effective behaviour change strategies. For example, a recent systematic review identified social support, problem solving and goal setting as effective strategies for behaviour change (Spahn et al. 2010), suggesting that LMPs are more likely to be successful if they incorporate these behavioural components. The HIPS LMP encouraged patients to set small achievable goals and to build on these once they had been achieved rather than patients setting larger goals that they may not attain. Providers considered the LMP to have helped patients take a more active role in their own health care, and to have motivated and supported patients to make lifestyle changes by providing group support from peers as well providing practical strategies and approaches to changing diet and physical activity.

\section{Maintaining patient lifestyle changes}

Maintenance of behaviour changes following LMPs is a key challenge and an issue identified by providers in this study. Evidence suggests that long-term follow up and support is required to maintain behaviour changes, particularly those pertaining to diet, physical activity and weight loss (Simkin- Silverman et al. 1998; Bowen and Beresford 2002; Winett et al. 2005). Following the completion of a LMP, follow up and reinforcement could be provided as part of routine general practice consultations, provided there is effective communication back to the practice from LMP coordinators. However, given time constraints in general practice, consideration should also begiven to options 
for long-term support of patients by the PN or by programs or services outside the practice. These could include telephone and Internet based support programs, for example the NSW Get Healthy Information and Coaching Service (NSW Department of Health 2009), and linking patients into existing community based nutrition and exercise programs, such as the national HeartFoundation Heartmoves exercise programs (NSW Department of Health 2004) and walking groups.

\section{Sustainability of LMPs within general practice settings}

Respondents felt that the PNs were important for the long-term sustainability and effectiveness of the LMP within the general practice setting as they were able to carry out many of the initial and follow-up assessment measurements and offer brief advice tailored to the patient's readiness for change. Other practice staff members were also able to share the workload by arranging appointments to referrals and follow-up visits. This shared teamwork approach has been found to be effective in our other research (Kirby et al. 2008; Wan et al. 2008; Taggart et al. 2009), providing GPs with the option to share their workload with other members of the practice.

Most respondents felt that there was a need for preventive services for people at risk of developing chronic disease and that these were currently lacking in the health system. They were keen to see the LMP provided on an ongoing basis but recognised that there were limited services available and local programs need to be developed. The HIPS LMP was coordinated by Divisions. As part of the Australian health reforms, the government is introducing Medicare Locals, a nation-wide network of primary health care organisations that build on the strengths of the current Divisions of General Practice Network to improve access to and integration of primary health care services (Roxon 2010). The new Medicare Locals will be well placed to play an important role in facilitating LMPs for people at risk of vascular disease and not just those with established chronic conditions, such as diabetes. There has been limited research examining how effective LMPs for prevention of chronic disease are when implemented in general practice in Australia (Harris et al. 2003). The Do It For Life program targets patients at 'high' risk of preventable chronic disease (The Flinders Program 2010) and a previous study in Victoria focussed on patients at risk of diabetes (Laatikainen et al. 2007). However, HIPS is the first known study in Australia that specifically targets patients at risk of vascular diseases (cardiovascular disease, renal disease and diabetes). Additionally, HIPS targeted patients aged 40-65 years, extending the reach of the federally funded LMPs, which are limited to patients aged 45-49 years. As chronic disease prevention is a high health priority for governments, more research is urgently required to extend the evidence base in this area.

\section{Limitations}

This study has several limitations. It was conducted in three urban and two rural Divisions in NSW and thus caution is needed in generalising the findings to other areas. The respondents were volunteers in a larger trial and are likely to represent providers with a particular interest in prevention, so their practice may not be typical of all general practice. However, the characteristics of providers are broadly similar to those of their professional groups in Australia (Britt et al. 2009).

\section{Conclusion}

The HIPS study has extended what is known about providing group interventions for patients at high risk of preventable chronic disease to include programs specifically targeting those at risk of vascular disease. Lifestyle modification programs have the potential to extend the influence of general practice beyond the consultation, and, if effective, contribute to reducing vascular disease. However, if they are to be sustained on a large scale, they will need to be organised to fit the routines of both general practices and participants. For the former, more work is needed, particularly around the role of PNs in prevention and arranging referral to LMPs. For the latter, flexible arrangements will be needed, together with ongoing support and follow up to assist maintenance. These developments will need to be supported beyond the practice level. The newly formed Medicare Locals will be well placed to facilitate LMPs for this target group. This will need to be carefully planned and evaluated to ensure they fit practice and participant routines and support sustained lifestyle changes. Further research will be required to implement this arrangement on a larger scale, as part of a national policy initiative.

\section{Conflicts of interest}

None declared. 


\section{Acknowledgements}

The study was funded by the National Health and Medical Research Council and the CIA was supported by an Australian Department of Health and Ageing Primary Health Care Research and Evaluation Program Fellowship.

E. Saurman conducted some of the interviews, and the authors acknowledge her contribution. The authors would like to thank the participating Divisions of General Practice, general practitioners, practice nurses and allied health professionals.

\section{References}

AGPN (2009) Lifestyle modification programs. Available at http://www. agpn.com.au/programs/prevention-of-type-2diabetes-program/lifestyle-modification-programs [Verified 8 September 2010]

AlHW (2008) 'Australia's health 2008.' Cat no. AUS 99. (AlHW: Canberra) Amoroso C, Harris M, Ampt A (2009) The 45 year old health check: feasibility and impact on practices and patient behaviour. Australian Family Physician 38(5), 358-362.

Bowen D, Beresford S (2002) Dietary interventions to prevent disease. Annual Review of Public Health 23, 255286. doi:10.1146/annurev.publhealth.23.100901.140555

Boyatzis R (1998) Transforming qualitative information: thematic analysis and code development. (Sage: Thousand Oaks, CA)

Britt H, Miller G, Charles J, Henderson J, Bayram C, Pan Y, Valenti L, Harrison C, Fahridin S, O’Halloran J (2009) 'General practice activity in Australia, 2008-09.' General practice series no. 25. Cat. no. GEP 25. (AIHW: Canberra)

Brotons C, Björkelund C, Bulc M, Ciurana R, Godycki-Cwirko M, Jurgova E, Kloppe P, Lionis C, Mierzecki A, Pin iro R, Pullerits L, Sammut MR, Sheehan M, Tataradze R, Thireos EA, Vuchak J (2005) Prevention and health promotion in clinical practice: the views of general practitioners in Europe. Preventive Medicine 40(5), 595-601. doi:10.1016/j.ypmed. 2004.07.020

COAG (2006) Council of Australian Governments. Available at http://www. coag.gov.au/coag_meeting_outcomes/200602-10/index.cfm\#health [Verified 8 September 2010]

Diabetes Prevention Program Research Group (2002) Reduction in the incidence of type 2 diabetes with lifestyle intervention or metformin. The New England Journal of Medicine 346(6), 393-403. doi:10.1056/ NEJMoa012512

DoHA (2005) 'General practice in Australia: 2004.' (Commonwealth Department of Health and Ageing: Canberra)

DoHA (2006) 45 year old health check (MBS item 717). (Commonwealth Department of Health and Ageing: Canberra) Available at http://www. health.gov.au/internet/wcms/publishing.nsf/Content/health-epc- 45check [Verified 8 December 2010]

DoHA (2009) 'Australia: the healthiest country by 2020 - national preventative health strategy overview.' (Commonwealth Department of Health and Ageing: Canberra)

DoHA (2010a) Divisions of General Practice program. (Commonwealth Department of Health and Ageing: Canberra) Available at http://www. health.gov.au/internet/main/publishing.nsf/Content/health-pcd- programs-divisionsindex.htm [Verified May 2011]

DoHA (2010b) Prevention of type 2 diabetes program - lifestyle modification programs. (Commonwealth Department of Health and Ageing: Canberra) Available at http://www.health.gov.au/internet/main/publishing.nsf/ Content/chronic-diab-prev-Imp [Verified 3 December 2010]

Eley D, Eley R (2009) How do GPs manage their inactive and overweight patients? A pilot study of rural GPs in Queensland. Australian Family Physician 38(9), 747-748.

Eriksson M, Hagberg L, Lindholm L, Malmgren-Olsson E, Osterlind J, Eliasson M (2010) Quality of life and costeffectiveness of a 3-year trial of lifestyle intervention in primary health care. Archives of Internal Medicine 170(16), 1470-1479. doi:10.1001/archinternmed.2010.301

Fanaian M, Laws RA, Passey M, McKenzie S, Wan Q, Powell Davies G, Lyle D, Harris MF (2010) Health improvement and prevention study (HIPS) - evaluation of an intervention to prevent vascular disease in general practice. $B M C$ Family Practice 11, 57. doi:10.1186/1471-2296-11-57

Frank O, Litt J, Beilby J (2004) Opportunistic electronic reminders - improving performance of preventive care in general practice. Australian Family Physician 33(1/2), 86-90.

Goodwin MA, Zyzanski SJ, Zronek S, Ruhe M, Weyer SM, Konrad N, Esola D, Stange KC (2001) A clinical trial of tailored office systems for preventive service delivery. The study to enhance prevention by understanding practice (STEPUP). American Journal of Preventive Medicine 21(1), 20-28. doi:10.1016/S0749-3797(01)00310-5

Harris SB, Petrella RJ, Leadbetter W (2003) Lifestyle interventions for type 2 diabetes: relevance for clinical practice. Canadian Family Physician 49, 1618-1625. 
Harris MF, Hobbs C, Powell Davies G, Simpson S, Bernard D, Stubbs A (2005) Implementation of a SNAP intervention in two divisions of general practice: a feasibility study. The MedicalJournal of Australia 183, s54-s58.

Hogg W, Lemelin J, Moroz I, Soto E, Russell G (2008) Improving prevention in primary care. Evaluating the sustainability of outreach facilitation. Canadian Family Physician Medecin de Famille Canadien 54, 712-720.

QSR International (2008) 'Nvivo8.' (QSR International: Melbourne)

Jackson Bowers E (2010) 'RESEARCH ROUNDup - How does teamwork support GPs and allied health professionals to work together? (Primary Health Care Research \& Information Service: Flinders University, Adelaide)

Kirby SE, Chong JL, Frances M, Powell-Davies G, Perkins DA, Zwar NA, Harris MF (2008) Sharing or shuffling-realities of chronic disease care in general practice. The Medical Journal of Australia 189, 77

Laatikainen T, Dunbar J, Chapman A, Vartiainen E, Heistaro S, Philpot B, Absetz P, Bunker S, O’Neil A, Reddy P, Best JD, Janus ED (2007) Prevention of type 2 diabetes by lifestyle intervention in an Australian primary health care setting: greater green triangle (GGT) diabetes prevention project. BMC Public Health 7, 249. doi:10.1186/14712458- 7-249

May C, Finch T, Mair F, Ballini L, Dowrick C, Eccles M, Gask L, MacFarlane A, Murray E, Rapley T, Rogers A, Treweek S, Wallace $P$, Anderson G, Burns J, Heaven B (2007) Understanding the implementation of complex interventions in health care: the normalization process model. BMC Health Services Research 7, 148. doi:10.1186/1472-69631187-1148

Medicare Australia (2011) Medicare Australia statistics. Available at https://www.medicareaustralia.gov.au/statistics/mbs_item.shtml [Verified 15 December 2010]

NSW Department of Health (2004) Heartmoves. Available at http:// fulltext.ausport.gov.au/fulltext/2004/nsw/heartmovesFull.pdf [Verified 3 December 2010]

NSW Department of Health (2009) New healthy weight coaching service. Available at http://www.health.nsw.gov.au/news/2009/20090222_00. html [Verified 3 December 2010]

Nutbeam D, Harris E (2004) 'Theory in a nutshell: a practical guide to health promotion theories.' 2nd edn. (McGrawHill: Sydney)

Passey M, Fanaian M, Lyle D, Harris MF (2010) Assessment and management of lifestyle risk factors in rural and urban general practices in Australia. Australian Journal of Primary Health 16(1), 81-86. doi:10.1071/ PY09061

PHCRIS (2011) Division and SBO profiles. Available at http://www.phcris. org.au/ divisions/profiles/index.php [Verified 31 May 2011]

Roxon N (2010) Medicare Locals - discussion paper on governance and functions. (Department of Health and Ageing: Canberra)

Sim MG, Wain T, Khong E (2009) Influencing behaviour change in general practice. Part 1 - brief intervention and motivational interviewing. Australian Family Physician 38, 885-888.

Simkin-Silverman LR, Wing RR, Boraz MA, Meilahn EN, Kuller LH (1998) Maintenance of cardiovascular risk factor changes among middle- aged women in a lifestyle intervention trial. Women's Health (Hillsdale, N.J.) 4(3), 255271.

Spahn JM, Reeves RS, Keim KS, Laquatra I, Kellogg M, Jortberg B, Clark NA (2010) State of the evidence regarding behavior change theories and strategies in nutrition counseling to facilitate health and food behavior change. Journal of the American Dietetic Association 110, 879-891. doi:10.1016/j.jada.2010.03.021

Taggart J, Schwartz A, Harris MF, Perkins D, Powell-Davies G, Proudfoot J, Fanaian M, Crookes P (2009) Facilitating teamwork in general practice: moving from theory to practice. Australian Journal of Primary Health 15, 24-28. doi:10.1071/PY08057

Taggart J, Dennis S, Williams A, Harris M, Newall A, Zwar N, Shortus T (2010) Effective interventions to improve health literacy associated with SNAPW risk behaviours. In '2010 primary health care research conference: program and abstracts'. (Primary Health Care Research and Information Service: Darwin) Available at http://www.phcris.org.au/ conference/browse. php?id=6709 [Verified 8 September 2010]

The Flinders Program (2010) The Flinders Program for chronic condition management information paper. Available at http://www.flinders.edu.au/ medicine/fms/sites/FHBHRU/documents/publications/FLINDERS\% 20PROGRAM\%2OINFORMATION\%20PAPER\%20FINAL_M.pdf [Verified 18 May 2011]

Tuomilehto J, Lindstrom J, Eriksson J, Valle T, Hamalainen H, Ilanne- Parikka P, Keinänen-Kiukaanniemi S, Laakso M, Louheranta A, Rastas M, Salminen V, Uusitupa MI (2001) Prevention of type 2 diabetes mellitus by changes in lifestyle among subjects with impaired glucose tolerance. The New England Journal of Medicine 344, 1343-1350. doi:10.1056/NEJM200105033441801 
Wan Q, Harris MF, Zwar N, Vagholkar S (2008) Sharing risk management: an implementation model for cardiovascular absolute risk assessment and management in Australian general practice. International Journal of Clinical Practice 62(6), 905-911. doi:10.1111/j.1742-1241.2008. 01769.x

WHO (2000) 'Global strategy for the prevention and control of noncommunicable diseases (A53/14).' (World Health Organization: Geneva)

Winett RA, Tate DF, Anderson ES, Wojcik JR, Winett SG (2005) Long-term weight gain prevention: a theoretically based Internet approach. Preventive Medicine 41(2), 629-641. doi:10.1016/j.ypmed.2004.12.005 Yarnall KSH, Pollak KI, $\emptyset$ stbye T, Krause KM, Michener JL (2003) Primary care: is there enough time for prevention? American Journal of Public

Health 93, 635-641. doi:10.2105/AJPH.93.4.635

Young J, Ward J (2001) Implementing guidelines of smoking cessation advice in Australian general practice: opinions, current practice, readiness to change and perceived barriers. Family Practice 18, 14-20. doi:10.1093/ fampra/18.1.14 